\title{
Exploration of the College Teaching Reform with Students as the Main Body
}

\author{
Shuyan $\mathrm{Yi}^{1, \mathrm{a}}$, Lina Liu ${ }^{2, \mathrm{~b}}$ \\ ${ }^{1}$ College of Humanities \&Sciences of Northeast Normal University, Changchun, 130117, China; \\ ${ }^{2}$ School of Liwang Experimental Primary School, Changchun, 130033, China. \\ ayishuyan2013@126.com, b403160937@qq.com
}

Keywords: Students; College; teaching reform; Main body.

\begin{abstract}
It is imperative to reform course in institution of Colleges and universities. This will not only help alleviate the current severe employment pressure, but also help improve the overall quality of students. Students are the main body of education, and the teaching reform of colleges should always focus on the students. Specifically, the schools, the counselors and the teachers should play their respective roles. First, the school should pay enough attention to the teaching reform, and laying down appropriate rules and regulations as well as effective measures. Second, the counselors should have a detailed understanding of each student's performance (including ideas, learning, discipline, etc.), and according to the performance of the students to carry out the corresponding guidance. Third, the teachers should teach students in accordance with their aptitude in the teaching process, and pay attention to the cultivation of students' quality. First, the teachers should pay more attention to practical activities, and make specific guidance for students' future career. Through the implementation of the teaching reform ideas, not only can promote the reform of higher education institutions, but also can improve the quality of the whole nation.
\end{abstract}

\section{Introduction}

With the slowdown in the pace of development and the adjustment of industrial structure and economic, the objective will have an impact on the structure of employment of workers. In order to meet the needs of social development, the Ministry of Education launched a new round of college education reform in 2015. The purpose of this reform is to make each students has a scientific research ability or talent to master some practical skills by the time four or five years of university study, Thereby enabling them to better serve the community. College students are the main body of college education. How to improve the students' comprehensive quality not only related to the future development of a student, but also related to the actual results of the whole reform.

How to improve the students' comprehensive quality not only related to the future development of a student, but also related to the actual results of the whole school reform. Therefore, understanding the students is the primary prerequisite for the establishment of a harmonious relationship between teachers and students.

\section{Instructors should often communicate with Students}

Students are in contact with the counselor the longest, most opportunities, most teachers understand the students, and they can be referred as the student's mentor. Compared with professional teachers, they have a natural advantage in understanding the students' ideological trends and their communication with the students.

At the time of the student just entering university school, counselors often serve as the role of the parents of students, acted as the most trusted teachers of the new students. When entering the University, in the face of a new unfamiliar environment, college students in the heart will have a strong sense of freshness to the school and the surrounding people. At this time, they will be relatively restrained in words and actions, and their temperament, ability extrinsic qualities will have 
a more intuitive performance. This is the time for them to show their nature and desire for acceptance, as well as the best time for others to know them. As the student's first teacher after he entered the university, the instructors should make full use of its functions, advantages, timely understand students, found that their advantages and disadvantages, timely choose ability outstanding students, preliminary established can normal operation of student cadres. Then, as an opportunity, in the use of student cadres to understand the students, the instructor can get rich information through the form of questionnaire and other forms of psychological investigation, so as to fully grasp all kinds of information of the students. It can be said that at this time to obtain first-hand information for the development of its guiding students has a significant practical significance. The student file has a student's growth learning experience and family situation, it is an important window to recognize the student, the counselors can be through the student files on their learning in primary and secondary schools, the body, thought, moral character and family, students and many other aspects have a direct insight. This method is convenient and effective, simple and feasible, for the teacher to establish a correct and clear judgment for the students; the cognition has important guiding significance.

In addition, the instructor can also through daily observation and feedback the student cadre, the dialogue with the students, the holiday to the students home for home visits and other forms of real time students to grasp the dynamic information, record each student's natural situation, to the student's family environment, the parents work, the study situation, the disposition psychology, the interest hobby and so on each aspect has the continuous attention.

In short, through the hands of the different periods of the materials, counselors can regularly on the students of the various manifestations of the comparative study. This will not only have a general judgment on the performance of students in school, but also through sustained attention to the understanding of the students, for their academic and career planning to provide useful help. It can be expected, if the instructor can have enough attention to the daily dynamics of students, to understand its recent ideological trends, giving timely guidance in its confusion, and promote its success, enable students has been in a positive, progressive growth, avoid such as due to the playing of the waste to learning, due to occurrence of the condition change wait for a phenomenon, and thus put an end to the occurrence of extreme mood extreme volatility as a result of the students and the suicide phenomenon.

\section{Teachers should teach Students in Accordance with Their Aptitude}

The teachers should cultivate students' moral and guide students to enhance. The students are learning the subject, teaching object, is the direct embodiment of teacher education achievement. It can be said that the teacher should understand the students, to develop a reasonable teaching strategy, will it be possible to achieve good teaching effect.

However, the actual situation of the university teachers are often responsible for the teaching of one or a few classes and the students also come from different classes and faculty, the situation of the students each other between are not very familiar make the teachers have great difficulty to know all the students. Therefore, how to let the teacher know students and the teaching effect is a topic worthy of further study. For at this stage the majority of university to implement management of student counselors in charge of the actual situation, the teachers should actively with the instructor to communicate from counselors where to get first hand information related to the situation of the students. At the beginning of the semester, each subject teachers need to seek information related to students' from the counselors there, in order to teach the students individual learning foundation, psychological characteristics and character traits situations such as roughly accomplish know fairly well. And then, according to the appropriate the teacher should adjustment of teaching strategies, in order to receive a good teaching effect.

After the preliminary understanding of students, the teachers available to enrich the students' information and to students were broadly categorized. Then in the preparing process to consider student's ability to accept, personality preferences of individual differences, the overall convergence principle of appropriate adjustments according to teaching content and style. At the same time, 
teachers should strengthen their contact and mutual understanding with the students, according to the characteristics of different types of students; use the implementation of different educational strategies.

For example: to the enthusiasm and active students, teachers should not only use his enthusiasm to encourage them to accept the challenge, but also give the appropriate performance opportunities, cultivate their interest. To this kind of students when they encounter problems, the teacher should guide the calmly and carefully treat the problem; avoid them because of carelessness, anticlimax leads to errors. The mucus type students tend to have strong self-confidence, emotional stability, patience, as long as the correct guidance for such students, you can set a good example for other students. The melancholic type students more introverted, with slowly words and deeds, indecision, the teachers to pay more attention to these students, encourage them to speak more, increase the opportunity to communicate with others for themselves. The bile type students respond quickly, speak positively, teachers should play the advantages of such students, so as to active classroom atmosphere. Only the preparatory work done, teaching work will be carried out very smoothly, is the so-called "Sharpening the axe will not interfere with the cutting of firewood".

In addition, the teachers and counselors often communication, will students recently in class performance, lateness and absenteeism and other abnormal performance timely feedback to the instructor, mutual negotiation strategy, to better guide the students positive, steady progress.

\section{Give full Play to the Role of Class Collective Fighting Fortress}

Chinese universities are mostly based on professional classification, class and grade as the unit to carry out the classification of education and management of students. Can say, class is the university the most basic management unit, is also a member of the interior are most familiar with each other, the collective honor sense of the strongest community groups, every college students have psychological destination is their university life in the most warmly home.

Class is the Battle Fortress of students' college life. A good class atmosphere and work style construction need of all members of the class cadres, especially leading role in dedication. Monitor is the leader of a class, and other cadres are the vanguard of the class construction, the quality of their works directly determine the achievements of the class. According to statistics, in the university study, the student's study result often takes the class as the unit to have the difference, to quantitative statistics, excellent class and poor grades and often have a greater difference with other classes. This difference in grades and class' style, proportional, and the class cadre personal ability and quality is directly proportional. Good class performance requires the management strategy and selfless dedication of the class cadre, especially the monitor.

In practical work, the monitor should have the vision of philosophy, pay attention to methods, rational planning of class work plans and objectives, focus on doing things proceed from the overall situation, conducting fair, lead by example, in the class and establish a good image; On the external side, the monitor should be timely understanding of the dynamics of each student in his class, together with other student cadres to deal with the problem of good students, regular report the class situation to instructor. On the problem not be effectively resolved, he should be timely communication with the instructor, to develop from a higher level of a reasonable solution. Other student cadres should assist the monitor to do class management work, in the whole classroom learning atmosphere to create an example, take the lead role; At the same time, they should pay more attention to the students' daily life, in time, through their own efforts to avoid the occurrence of some negative phenomena; the students cadres frequently communicate each other, In order to make the class to become a unity of the collective. Good individuals can drive the overall progress of the group, the fine style of study can promote the whole class performance rise, and the role of student cadres cannot be ignored.

According to the feedback from the teachers, in the learning process, the differences between different classes of students in the same profession will gradually increase, by its own class atmosphere, style of study, students in the learning process of the learning attitude, effort level 
differences. The style of study is good, class collective unity of class, most of the students have a positive enthusiasm for learning, the entire class of academic performance is also better than other classes. If the style of study is not correct, poor cohesion of class, the student performance relatively lax, to learn without strong thirst for knowledge, truancy phenomenon has occurred, class average score to lower than other classes.

In the face of the same teaching content, the same teacher, why there will be such a big difference among the students? Obviously, in the situation of the students originally quality is almost the same, this kind of changes is mainly caused by the late development, with the student own factor and the surrounding environment have great relationship. You can imagine, if in an atmosphere of unity, the students must want to progress, to fight for their position in the collective, rather than deliberately to pull the collective back; Even if the students have some negative thoughts, if the class cadres can be timely to remind, counselors can be timely guidance, the students will soon give up the wrong idea, back to the correct way forward.

Therefore, the class is the most basic group of students in the college community organizations, so that student's collective sense of honor of the bearer is an important battle fortress. The student cadres is the vanguard of the students, is the creator of good class atmosphere in the class and maintenance, should better play the exemplary vanguard roles. The counselor is the whole thing of the regulators and guide should pay attention to the training and selection of student cadres, so that it can better serve the students. Only when they carry out their duties, in order to ensure the whole class moving in the right direction, promote ll students to become useful.

\section{Summary}

"All for students, for all students". Only the teachers fully understand the students, trying to fully mobilize the initiative of students, to achieve the ultimate goal of higher education reform. Colleges and universities teaching reform must pay attention to the students the main body, for students of different personality in advance of its future has a clear planning. In the specific teaching process, teachers, counselors, class collective and so on together, make the work be implemented to each student individual. Focus on a variety of practical activities, give full play to the initiative of students, and strive for each student to be able to succeed, truly realize the national advocate of college education reform.

\section{References}

[1]. K.N. Wu, On the foundation of successful education reform. Educational Research, General. 384 (2012) No. 1, pp.24-31.

[2]. Y.F. Yang. Some considerations on deepening the comprehensive reform in education. Educational Research. General. 408 (2014).No. 1, pp.4-19.

[3]. X. Mao. Study on the characteristics of the competency of college counselors and the Countermeasures. Studies in Ideological Education. General. 232 (2014) No. 1, pp.102-104.

[4]. L.S.Wang. Study on the advantages and deficiencies of the "instructor system" in American Universities. Education for Chinese After-school (Theory). (2014)No. 7, pp.346-352.

[5]. K.D. Yin. Strengthening the construction of dormitory culture and improve students' comprehensive quality of college students. Education Exploration. (2008) No. 1, pp. 4-5.

[6]. G.X. Lin. My opinion on the construction of college student cadre ranks. Journal of Yunnan Institute of Socialism. (2014) No. 3, pp. 147-148. 